in vivo $32: 999-1007$ (2018)

doi:10.21873/invivo.11340

Review

\title{
Cysts and Pseudocysts of the Oral Cavity: Revision of the Literature and a New Proposed Classification
}

\author{
DARDO MENDITTI ${ }^{1}$, LUIGI LAINO ${ }^{2}$, MARINA DI DOMENICO $^{3}$, GIUSEPPE TROIANO $^{2}$, \\ MARIO GUGLIELMOTTI ${ }^{1}$, SARA SAVA ${ }^{1}$, ANTONIO MEZZOGIORNO ${ }^{4}$ and ALFONSO BALDI ${ }^{5}$ \\ ${ }^{1}$ Department of Dentistry, Orthodontics and Oral Surgery, University of Campania, Naples, Italy; \\ ${ }^{2}$ Department of Clinical and Experimental Medicine, University of Campania, Naples, Italy; \\ ${ }^{3}$ Department of General Pathology and Biochemistry, University of Campania, Naples, Italy; \\ ${ }^{4}$ Department of Mental Health and Physics, Preventive Medicine, University of Campania, Naples, Italy; \\ ${ }^{5}$ Department of Environmental, Biological and Pharmaceutical Sciences and \\ Technologies, University of Campania, Naples, Italy
}

\begin{abstract}
This article includes a comprehensive and up-todate review on the cysts of the oral cavity. Several classifications of odontogenic (OC) and non-odontogenic (non$O C)$ oral cysts and the surrounding regions have been proposed. We suggest a new critical classification based on an established relationship between anatomical area, histological origin and clinical behavior (frequency, rate of recurrence, malignant potential). Moreover, the differential cytokeratin (CKs) expression of the various cysts is reported as epitheliumspecific markers of differential diagnosis. Finally, issues related to differential diagnosis and therapeutic approaches of the cysts included in the two groups are described.
\end{abstract}

Oral cysts (1-8) are divided into two major groups based on odontogenesis: odontogenic cysts (OCs) and non-odontogenic cysts (non-OCs). The first group is characterized by specific odontogenic markers, histological similarities with odontogenic structures and anatomical considerations (9).

The second group $(1,3)$ includes cysts that originate from specific areas or organs of the oral cavity such as salivary cysts, naso-palatine duct/mid-palatine cysts and nasolabial cysts. In this group are included also some cysts, that are

This article is freely accessible online.

Correspondence to: Prof. Alfonso Baldi, Department of Environmental, Biological and Pharmaceutical Sciences and Technologies, Second University of Naples, Caserta, Italy. Tel: +39 0815782338, e-mail: alfonsobaldi@tiscali.it

Key Words: Cysts, pseudo-cysts, cytokeratin, oral cavity, diagnosis, classification, review. ubiquitous in the body, such as dermoid cysts, lymphoepithelial cysts, and aneurysmal bone cysts.

OCs arise from the tooth-producing tissues; alternatively, they originate from the remnants of dental lamina epithelium entrapped within the gingival named epithelial rests of "Serres" (8-10), or the epithelial remains of the "Malassez" $(2,10-12)$. These cellular remnants fall within the concept of the post-functional state of the dental lamina, which has limited growth potential. These two types of embryological residues can generate two different types of dental cysts (5, 13). From the remnants of Serres takes origin the periodontal cyst, and the orthokeratocyst, that is a more aggressive type of cyst with a neoplastic variant5. From the residues of Malassez originates the inflammatory radicular cyst (9). For this last type of cyst, an infectious and/or inflammatory stimulus acting on a genetic predisposition has been proposed as the first pathogenic event causing the proliferation of cellular odontogenic remnants (11-14).

Cytokeratins (CKs) are epithelium-specific markers of differentiation and have been proposed as ideal markers for differential diagnosis of these cysts, being involved in physiological odontogenesis (14-23). In detail, CKs 5 and 14 are expressed in the basal cell layer of both the keratinized and non-keratinized epithelia, with a reduction in the upper layers; CKs 1 and 10 are specific to the spinous layer; CK 19 is present in the basal stratum of the non-keratinized epithelia; CKs 4 and 13 are specific for supra-basal cells of the tongue epithelium; $\mathrm{K} 2 \mathrm{p}$ is present in the supra-basal epithelial cells of the hard palate and gingiva. During odontogenesis CKs have a peculiar pattern of expression: CK7 is expressed in the "stellatum reticulum" at the early bell stages along with CK14; these two CKs, together with CK 19, are also expressed in the cells of the enamel epithelium; 
Table I. Cysts and pseudocysts of the oral cavity.

1) CYSTS AND PSEUDOCYSTS OF ORAL BONE TISSUE AND PERIODONTAL

a) Odontogenic cysts

- "Inflammatory origin"

Radicular-necrotic cyst

Collateral inflammatory cyst (Paradental cyst, Juvenile paradental cyst)

- "Development origin" DC (dentigerous cysts): follicular, germinal, eruptive cysts

- Periodontal tissue (parodontal cysts)/BOC

- Gingival cysts of infants (newborn gingival cysts, dental lamina cysts, Bohn's nodules)

b) Non-odontogenic cysts

- Mid-palatal-raphe non-odontogenic cysts of infants (Epstein's pearls)

- Nasopalatine duct/midline palatine cyst

c) Cysts of so-called "Globulo-maxillary area"

d) Cysts with malignant variants and misdiagnosis

OOC (orthokeratinized odontogenic cyst)

COC (calcifying odontogenic cyst)

Glandular cysts (GOC: glandular odontogenic cyst; sialo-odontogenic cyst)

e) Cysts and pseudocysts of the maxillary sinus

f) Pseudocysts of the bone basis of the oral cavity: SBP (Solitary bone pseudo-cysts); ABP (aneurysmal bone cysts)

2) SOFT TISSUE NON-ODONTOGENIC CYSTS

- Cysts related to the lymphatic tissue (cystic hygroma; lymphoepithelial cysts), thyroglossal duct cyst

- Salivary cysts and pseudo-cysts

- Nasolabial cyst (synonyms: nasoalveolar cyst, Klestadt's cyst)

- DEC (dermoid and epidermoid congenital cysts)

CK14 is present at early "bell stage" and replaced by CK19 in differentiated ameloblasts; CKs 7 and 13 are found in the "rests of Serres" (16-18). It has been reported that the structure of CKs, as well as, their expression within the cells may be altered depending on environmental conditions (e.g. inflammation) $(15,19-21)$ and on changes in cellular function. Therefore, the detection of an altered expression is useful for the differential diagnosis of various diseases such as cysts and tumors. Indeed, CKs 5 and 6 are present in all layers of the odontogenic cysts, CK13 is expressed in the supra-basal cell layer of all odontogenic cysts, while CK20 is negative in all odontogenic cysts (18).

In this article, we propose a new classification for the cysts of the oral cavity. Briefly, we divide the different types of cysts in two major groups: 1) Cysts of oral bone tissue and periodontal, and 2) Soft tissue non-odontogenic cysts. Each group is, then, composed of different sub-groups, based on the established relationship with anatomical area, histological origin and clinical behavior (frequency, rate of recurrence, malignant potential). Table I depicts this classification with all the sub-groups. Following is a comprehensive description and discussion on this classification.

\section{Cysts and Pseudocysts of Oral Bone Tissue and Periodontal}

a) Odontogenic cysts of "inflammatory origin". Radicularnecrotic cyst. The most common cyst of the oral cavity is due to the loss of the biological barrier (the pulp of the tooth) that follows from carious lesions or dental trauma $(6,13,14)$ with pulp necrosis and derives from the cellular remnants of the "Malassez". They can lead to the formation of an inflammatory radicular-necrotic cyst (RC), that can be periapical or peri-radicular. First event is the formation of a granuloma, that subsequently gives rise to a cyst, whose epithelium expresses a specific odontogenic CK such as 19 in the superficial cell layers (24-26) and co-expresses CK5 in the cyst lining (18). A peculiar variant of RC is considered the Residual Radicular Cysts that develop from apical granulomas or residual fragments of $\operatorname{RC}(5,6)$.

Collateral inflammatory cyst (Paradental cyst, Juvenile paradental cyst). These cysts have overlapping histological features with RCs and their etiology is also considered inflammatory or meta-traumatic $(3-5,27)$. The inflammatory collateral cyst is located on the lateral side of a vital tooth and is the result of an inflammatory chronic process in the periodontal pocket (24-26). The juvenile paradental cyst of the lower molars (first-second) is located in the root area of the affected teeth of a young patient or distally to a lower wisdom tooth in adults (with appearance of pericoronitis) (27-29). These lesions are considered the same entity, regardless of localization (30). The histological features of these cysts are indistinguishable from those of the inflammatory RCs and this appearance emphasizes the origin from the remains of the Mallasez (14, 30-33). 

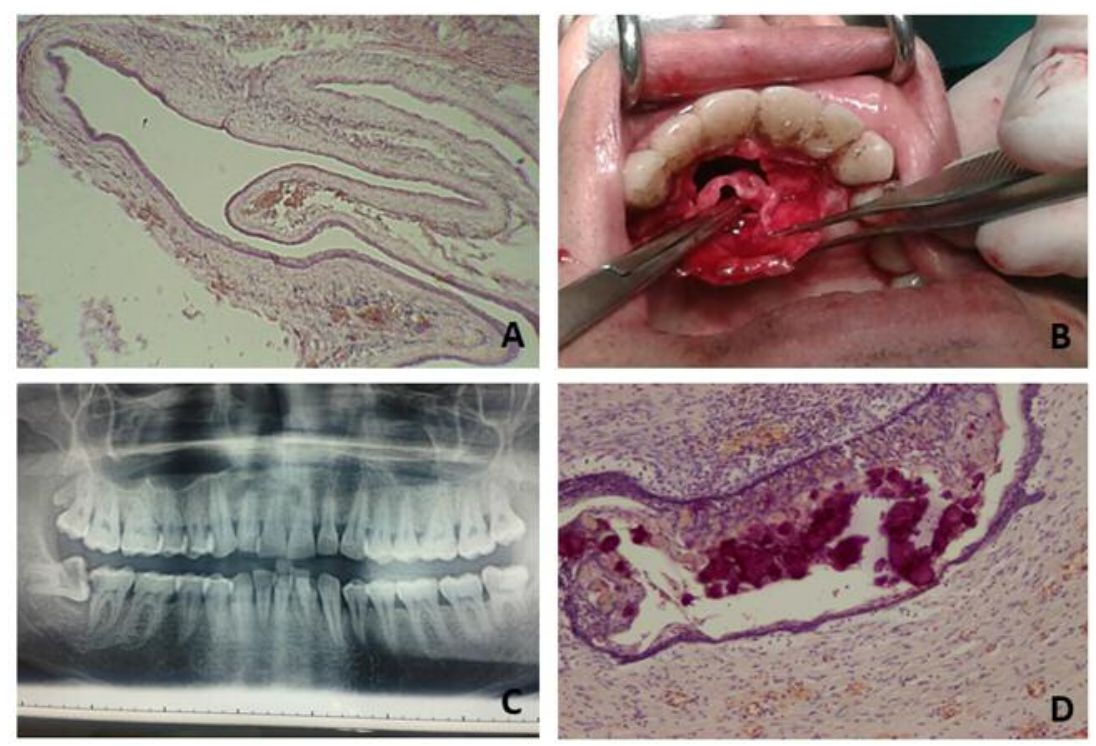

Figure 1. Examples of different cysts of the oral cavity. A: Dentigerous cyst-Follicular cyst: cystic lumen is lining by stratified squamous epithelium B: Nasopalatine duct cyst: an intraoperative phase is depicted. C: Cyst of the globule-maxillary area (arrow): characteristic imaging that not presents always the same histological features at microscopic observations. D: Calcifying Odontogenic Cyst: histological feature of ghost cells identified as deep blue-purple areas.

It is important to differentiate these cysts from other radiolucent jaw lesions, such as unicystic ameloblastoma, keratocystic odontogenic tumor (KCOT), dentigerous cysts (DC), LPC. CKs expression can aid to make a differential diagnosis through a combination of immunohistochemical markers such as CK10, CK13, CK17, perlecan, PCNA and UEA, to discriminate between RC and the other pathological conditions (31-33).

b) Odontogenic cysts of "development origin". Dentigerous cysts $(D C)$. These cysts surround the crown of a tooth that has not migrated into the oral cavity and are named follicular, germinal, or eruptive cysts (Figure 1A) (7). The "primary event" is an accumulation of pathological fluid in the layer of the reduced enamel epithelium or between it and the crown of an un-erupted tooth. In this type of cysts, CK 5, 6, 19 are expressed, while CK7 is absent (18).

Periodontal tissue (parodontal cysts; Botryoid cyst). Because they are of dental origin and the periodontal tissue is contiguous to the teeth and bone, they form a single nosological-group, such as "cysts of the periodontal tissues". The "cyst of the newborn" is its particular form discussed separately later. The cysts which affect the periodontal tissue are gingival cysts (frequently of the adults) (34) and periodontal cysts (lateral parodontal cyst: LPC; its variant: botryoid cyst) $(4,31,34-37)$ are unicystic (with differential diagnosis versus ameloblastoma cystic and "essential bone defects") (36). There are two or three layers of flattened cells mimicking a squamous epithelium; with a careful search, it is possible to find areas of nodular type thickening and clear cells rich in glycogen (13). The LPC may have a variant, multilocular, defined as "botryoid cyst". It can arise either from the remnants of Serres incorporated into the periodontal tissue, or, on the basis of an alternative hypothesis, from the reduced enamel epithelium of the follicle which expands to occupy a space in the periodontal ligament during the eruptive phase producing a parodontal cyst (38), while a portion of this may remain in the gum after the eruption forming a gingival cyst (39-42). LPCs are positive for CK13 and CK17 in the surface layers and perlecan and Ulex European Agglutinin (UEA) on the cell border of the whole layer, negative for CK10 (26). These cysts are made in relation to "remains of Malassez", causing confusion: ERM expresses CK19 and periapical granuloma is positive for CK $4 / 13$, while $\mathrm{RC}$ are positive for CK13 and $19(8,18,24,25,29)$.

Botryoid odontogenic cyst (BOC). BOC is a rare pathological multilocular cyst $(43,44)$ with or without proximity to a root of tooth, considered a variant of the LPC (44-46), derived from more groups of converging cellular debris of Serres. However, because of the presence of mucous cells and of the columnar cells (metaplastic type) $(16,20,45-47)$, it has been also considered to represent a variant of glandular odontogenic cyst (GOC) (3). CK 18,13, specific for "rests of Serres", show the origin from the odontogenic tissues (16, 
37, 48). Differential diagnosis to ameloblastoma can be made by CD56 and calreatin which are negative in BOC (45).

Gingival cysts of infants (newborn gingival cysts, dental lamina cysts, Bohn's nodules). They are present in newborns with developmental origin from the remains of the dental lamina $(4,49-52)$. The epithelium lining is squamous with areas of parakeratosis, keratin fills the cavity (53).

c) Non-odontogenic cysts. Mid-palatal-raphe non-odontogenic cysts of infants (Epstein's pearls). These lesions present similar histological/ clinical features to gingival cysts $(50,54-$ 56). Mid-palatal-raphe cysts arise from non-odontogenic epithelial remnants (52) after median palatal fusion.

Nasopalatine duct/ midline palatine cysts. The nasopalatine duct (NPD; Figure 1B) (54-57) represents the connection between the vomero-nasal organ and the nasal and oral cavities in many mammals, thus connecting the olfactory and the taste functions. Epithelial cells, organized in clusters or cords, may be present in the incisive canal of the maxilla. Unknown causes could stimulate the proliferation of these epithelial remnants, causing the formation of a cyst with a squamous or, more rarely, cylindrical and ciliated epithelium layer.

d) Cysts of the so-called "globulomaxillary area"

The cysts in this anatomical area (Figure 1C) frequently constitute a diagnostic and clinical problem (58). Globulemaxillary cysts were included in a group of cysts arising from an altered development, defined as "fissural cysts", but this pathogenesis is not accepted any more (59-64). These cysts display constant radiological and clinical features (58, 62-64), however they do not present always the same histological features: stratified squamous (odontogenic), parakeratinic (ortokeratocystic) or cylindrical respiratory (non-odontogenic) epithelium has been described in these cysts $(65,66)$. Indeed, in this group of cysts, we can include intraosseous cysts that develop between the roots of the lateral incisor and the canine teeth, causing their divergence (so-called globule-maxillary properly). Furthermore, cysts originating from the respiratory epithelium remained trapped in the globule-maxillary site and parodontal cyst. It is important to underline the fact that in this site it is possible to find also neoplastic cysts $(67,68)$.

e) Cysts with malignant variants and misdiagnosis. Some oral cysts present neoplastic variants (3). In our opinion, it seems more useful to consider in the classification a specific group of cysts designed as "cysts with tumor variants and possible misdiagnosis", such as the calcifying odontogenic cysts (69-71), the orthokeratinized odontogenic cyst (72-75), and the glandular odontogenic cyst $(71,72)$.
Orthokeratinized odontogenic cyst (OOC). OOC, is a cyst characterized by keratinized lining epithelium. When the epithelium displays significant parakeratosis or orthokeratosis, the term keratocystic odontogenic tumor (KCOT) is preferred, because this cyst is clinically more aggressive with a tendency to recur (74-76). Interestingly, these two cysts show a different pattern of expression for CKs: OOC expresses CK 1, 2, 10, and loricrin, while KCOT expresses CK 4,10,13,16 and 17, and 19, similarly to the dental lamina (18-23, 50, 75-79). Very importantly, from the clinical point of view, is the possibility to distinguish these cysts from ameloblastoma, taking advantage from the differential immunohistochemical expression of CD-56, CD-105 and calreatin $(36,71,74)$.

Calcifying Odontogenic Cyst (COC). We can distinguish three entities: simple intra-osseous COC, extra-osseous peripheral $\mathrm{COC}$ and the malignant form Calcifying Cystic Odontogenic Tumor (CCOT) $(21,23,70-72,79-81)$. COCs radiologically show a cystic imaging with small scattered areas of calcification, often resembling an odontoma (82). COCs (Figure 1D) have a peculiar histological pattern with an epithelial lining with a basal layer of columnar cells and an overlying epithelium, thick and vacuolated. Moreover, groups of eosinophilic cells with not stainable cellular structures are visible in the epithelial lining or in the connective tissue capsule or in both. These cells are named "ghost cells" and are considered dystrophic cells with aberrant keratinization or apoptotic cells with intracellular calcification (82-85). Ghost cells are present in different pathological entities, such as craniopharyngioma, odontoma, pilomatrixoma, ameloblastic fibroma and some visceral tumors (71). They accumulate some substances during the differentiation process, losing the cytoskeletal components and becoming CK10/13 negative (18). CKs 10/13 are, on the contrary, present in the upper layer of the cyst and CK14 is expressed in the basal layer. P63 expression seems evident in all layers of COC examined (85).

Glandular cysts (Glandular odontogenic cyst: GOC; sialoodontogenic cyst). GOC present epithelial cells arranged in glandular structures, with groups of acidophilic cuboidal or columnar cells, sometimes with papillary growth and projections into the cyst-like spaces (86-93). These cysts are in differential diagnosis with the central mucoepidermoid carcinoma (90). This differential diagnosis is based on the diverse immunohistochemical expression of MASPIN (mammary serine protease inhibitor) and of the tumormarkers Ki67 and p63 (88-93). The location within the bone or in the soft tissue has an important role in determining the more appropriate surgical protocol $(87,91,93)$.

f) Cysts and pseudocysts of the maxillary sinus. We think that it is important to report in this classification also cysts and 
pseudo-cysts primitive of this anatomical region (94-103). The primary cysts of the maxillary sinus are of three types: a) true cysts, due to an occlusion of the excretory ducts of the sinus mucous glands; b) mucoceles, formed from the non-external drainage of normal mucous; c) secondary mucoceles, that result from post radical sinus surgery, probably due to residues of sinus mucosa forming a new mucocele in a closed compartment. The pseudocysts are formed between the inner surface of the bone wall and the connective tissue layer, the sinus mucosa remaining on the outside. Their etiology remains unknown, although allergies, inflammation of the maxillary sinus, and mucosal odontogenic inflammation have been considered $(94,99)$ Sometimes, the secondary odontogenic cysts (mostly follicular and radicular-necrotic), can develop in the bone base of the upper jaw and invade the maxillary sinus. These cysts are named "intrusive sinus oral cysts".

g) Pseudocysts of the bone basis of the oral cavity (Solitary bone pseudo-cysts: SBP; aneurysmal bone cysts: ABP). SBPs are devoid of any epithelium lining and are considered of traumatic origin $(36,104)$. They are also known as bone pseudo-cysts or bone traumatic pseudo-cysts. ABPs are blood-filled sinusoidal or cavernous spaces without cystic epithelium $(105,106)$. The pathogenesis of these cysts is very similar to that of SBPs: a trauma can cause a bone hemorrhage and the clot may not be re-canalized leaving a cavity devoid of content (bone pseudo-cyst) or may present continuous micro-hemorrhages that may lead to the local reaction of macrophages (giant cell granuloma), or a vascular dilatation. Recently ABPs have been related to a ubiquitous protease USP-6 mapped on cromosoma16q22, that may be used as a diagnostic tool (107).

\section{Soft Tissue Non-Odontogenic Cysts}

In this group we consider: cysts related to the lymphatic tissue (cystic hygroma and lymphoepithelial cysts), and thyroglossal duct cyst (108-110).

Salivary cysts and pseudo-cysts. They should be referred to as salivary duct cysts and pseudo-cysts $(111,112)$. These cysts may be surrounded by salivary tissue and, thus, considered as retention cysts with an epithelial lining composed of one or two layers of flat or cuboidal epithelial cells. Alternatively, they may represent an extra-vasation of mucous in the peri-glandular connective tissue and, thus, considered pseudo-cysts by a rupture of the salivary duct with a partial epithelial lining, or mucous extra-vasation cysts.

The salivary retention cyst should be considered as a pseudo-cyst but this condition is the evolution of a process that begins with the formation of a retention cyst, and therefore it is considered as a "primary cause" of the salivary accumulation. Histologically, it may present oncocyte-like cells, a pseudo-stratified columnar epithelium or a stratified squamous epithelium. Ranula represents a mucocele of the floor of the mouth due to salivary accumulation in sublingual or submaxillary followed by its rupture and extravasation of saliva in the surrounding connective tissue. Since this happens frequently and prematurely, most of the ranulas do not have epithelial coatings. Ranulas can be located above the mylohyoid muscle (the simple type) or can grow downwards assuming an" hourglass shape" (the complex type or pluningranula) (110-112).

Nasolabial cyst (synonyms: naso-alveolar cyst, Klestadt's cyst). The concept that it is a fissural cyst, because it is related to the globule-maxillary cyst as its peripheral form is no longer valid, because there is no evidence of epithelial interruption of the interactions of his three embryological processes $(56,113-116)$. Histologically it consists of a cyst lined by a bi-layered epithelium with a cuboidal basal layer, sometimes pseudo-stratified, with goblet cells and areas of squamous metaplasia. CKs 5 and 6 are expressed in the basal layer cells, while CKs 7 and 19 are positive in all layers. The mucin in the goblet cells is MUC-2 and MUC-5AC positive similarly to the human lacrimal organs $(113,116)$. It is possible to speculate that it is a developmental nonodontogenic cyst of the soft tissue originating from the lower portion of the naso-lacrimal duct (116).

Dermoid and epidermoid congenital cysts (DEC). They (CK10 positive) derive from embryonic pluripotential cells trapped during the early weeks of intrauterine life; they, subsequently, develop into one or into all three ectoderm, mesoderm and endoderm tissues. The term "dermoid cyst" often refers to all types of these lesions (117-119). DEC are ubiquitous in the human body in sites where the embryonic parts fuse together. In the oral cavity they are classified as non-odontogenic cystic lesions of the soft tissue of the midline sites: the floor of the mouth (sublingual or submental), the tongue, cheek, parotid gland, mandibula $(30,112,118)$.

\section{Conclusion}

A precise classification of cysts will always be subject to continuous revisions based on continuous scientific updates, however, it should be essentially based on the histological and clinical features of these diseases. The proposed classification takes into account the site of the primary growth, the histological origin, the frequency, the recurrences, and the potential malignancy, so drawing attention to those cysts that may present uncertainty concerning their immediate diagnosis. The use of new technologies such as the confocal laser microscope and new acquisitions on biology and genetic alterations in odontogenic lesions $(120,121)$ will be able to 
add new data to the classification of the individual types of cysts. It is plausible to assume that in the future it will be possible to compile specific modules for each type of dental cysts with its peculiar structural and molecular features. This will allow a quick and very efficient comparison between the different types of cysts with a fast and safe diagnosis also versus tumors of the oral cavity.

\section{References}

1 Kramer IRH: Changing views on oral disease. Proc R Soc Med 67: 271-276, 1974.

2 Menditti D, Laino L, Milano M, Caputo C, Boccellino M, D'Avino A and Baldi A: Intraoral lymphoepithelial carcinoma of the minor salivary glands. In Vivo 26: 1087-1089, 2012.

3 Philipsen HP and Reichart PA: Revision of the 1992-edition of the WHO histological typing of odontogenic tumours. A suggestion. J Oral Pathol Med 31: 253-258, 2002.

4 Robson CD: Cysts and tumors of the oral cavity, oropharynx, and nasopharynx in children. Neuroimaging Clin N Am 13: 427-442, 2003.

5 Kumar M, Nanavati R, Modi TG and Dobariya C: Oral cancer: Etiology and risk factors: A review. J Cancer Res Ther 12: 458463, 2016.

6 Philipsen HP and Reichart PA: Classification of odontogenic tumours. A historical review. J Oral Pathol Med 35: 525-529, 2006.

7 Menditti D, Laino L, Cicciù M, Mezzogiorno A, Perillo L, Menditti M, Cervino G, Lo Muzio L and Baldi A: Kissing molars: report of three cases and new prospective on aetiopathogenetic theories. Int J Clin Exp Pathol 8: 1570815718, 2015.

8 Speight, PM and Takata T: New tumour entities in the 4th edition of the World Health 8. Organization Classification of Head and Neck tumours: odontogenic and maxillofacial bone tumour. Virchows Arch 472: 331-339, 2018.

9 Stoll C, Stollenwerk C, Riediger D, Mittermayer C and Alfer J: Cytokeratin expression patterns for distinction of odontogenic keratocysts from dentigerous and radicular cysts. J Oral Pathol Med 34: 558-564, 2005.

10 Menditti D, Laino L, Mezzogiorno A, Sava S, Bianchi A, Caruso G, Di Maio L and Baldi A: Oral benign fibrous histiocytoma: two case reports. Cases J 2: 9343, 2009.

11 Haku K, Muramatsu T, Hara A, Kikuchi A, Hashimoto S, Inoue $\mathrm{T}$ and Shimono M: Epithelial cell rests of Malassez modulate cell proliferation, differentiation and apoptosis via gap junctional communication under mechanical stretching in vitro. Bull Tokyo Dent Coll 52: 173-182, 2011.

12 Mosqueda-Taylor A: New findings and controversies in odontogenic tumors. Med Oral Patol Oral Cir Bucal 13: 555$558,2008$.

13 Saraf PA, Kamat S, Puranik RS, Puranik S, Saraf SP and Singh BP: Comparative evaluation of immunohistochemistry, histopathology and conventional radiography in differentiating periapical lesions. J Conserv Dent 17: 164-187, 2014.

14 Philipsen HP, Reichart PA, Ogawa I, Suei Y and Takata T: The inflammatory paradental cyst: A critical review of 342 cases from a literature survey, including 17 new cases from the author's files. J Oral Pathol Med 33: 147-155, 2004.
15 Schlage WK, Ulles H, Riedricmhsa D, Uhna RI and Eredesai A: Cytokeratin expression patterns in the rat respiratory tract as markers of epithelial differentiation in inhalation toxicology. Determination of normal nytokeratin nxpression patterns in nose, larynx, trachea, and lung. Toxypathology 26: 324-343, 1998.

$16 \mathrm{Lu}$ DP, Tatemoto Y, Yokoyama T, Kimura $\mathrm{T}$ and Osaki T: Cytokeratin expression patterns in jaw cyst linings with metaplastic epithelium. J Oral Pathol Med 31: 87-94, 2002.

17 Takeda Y, Oikawa Y, Furuya I, Satoh M and Yamamoto H: Mucous and ciliated cell metaplasia in epithelial linings of odontogenic inflammatory and developmental cysts. J Oral Sci 47: 77-81, 2005.

18 Chatterjee S: Cytokeratin in health and disease. J Oral Maxillofac Surg 3: 198-202, 2012.

19 Selvi F, Tekkesin MS, Cakarer S, Isler SC and Keskin C: Keratocystic odontogenic tumors: predictive factors of recurrence by Ki-67 and AgNOR labelling. Int J Med Sci 9: 262-268, 2012.

20 Hobbs RP, Lessard JC and Coulombe P: Keratin intermediate filament proteins - novel regulators of inflammation and immunity in skin. J Cell Sci 125: 5257-5258, 2012.

21 Maheswaran T, Ramesh V, Oza N, Panda A and Balamurali PD: Keratin metaplasia in the epithelial lining of odontogenic cysts. J Pharm Bioallied Sci 6(S1): 110-112, 2014.

22 Rajalbandi SK and Gothe P: Comparison of immuunohistochemical expression of CD-10 in odontogenic cysts. J Clin Diagn Res 8: ZC35-ZC38, 2014.

23 Moll R, Divo M and Langbein L: The human keratins: biology and pathology. Histochem Cell Biol 129: 705-733, 2006.

24 García CC: Expression of cytokeratins in epithelialized periapical lesions. Oral Surg Oral Med Oral Pathol Oral Radiol Endod 107: 43-46, 2009.

25 Chrcanovic BR, Reis BM and Freire-Maia B: Paradental (mandibular inflammatory buccal) cyst Head Neck Pathol 5: 159-164, 2011.

26 Tsuji K, Wato M, Hayashi T, Yasuda N, Matsushita T, Ito T, Gamoh S, Yoshida H, Tanaka A and Morita S: The expression of cytokeratin in keratocystic odontogenic tumor, orthokeratinized odontogenic cyst, dentigerous cyst, radicular cyst and dermoid cyst. Med Mol Morphol 47: 156-161, 2014.

27 Ravi Prakash A, Sreenivas RP and Rajanikanth M: Paradental cyst associated with supernumerary tooth fused with third molar: A rare case report. J Oral Maxillofac Pathol 16: 131-133, 2012.

28 Borgonovo AE, Grossi GB, Maridati PC and Maiorana C: Juvenile paradental cyst: presentation of a rare case involving second molar. Minerva Stomatol 62: 397-404, 2013.

29 Ackermann G, Cohen M and Altini M: The paradental cyst: a clinicopathological study of 50 cases. Oral Surg Oral Med Oral Pathol 64: 308-312, 1987.

30 Menditti D, Laino L, Ferrara N and Baldi A: Dermoid cyst of the mandibula: a case report. Cases J 1: 260, 2008.

31 Ida-Yonemochi H, Satokata I, Ohshima H, Sato M, Yokoyama T, Yamada Y and Saku T: Morphotic roles of perlecan in the tooth enamel organ: an analysis of overexpression using transgenic mice. Matrix Biol 30: 379-388, 2011.

32 Farach-Carson MC, Warren CR, Harrington DA and Carson DD: Border patrol: insights into the unique role of perlecan/heparan sulfate proteoglycan 2 at cell and tissue borders. Matrix Biol 34: 64-79, 2013. 
33 Tsuneki M, Yamazaki M, Cheng J, Maruyama S, Kobayashi T and Saku T: Combined immunohistochemistry for the differential diagnosis of cystic jaw lesions: its practical use in surgical pathology. Histopathology 57: 806-813, 2010.

34 Park JC, Cheung WS and Campbell KM: A Rare Case of Gingival Cyst in a Child. J Dent Child 84: 44-46, 2017.

35 Menditti D, Laino L, De Marco G, De Rosa A, Mellone P and Baldi A: Unicystic ameloblastoma of the mandible. In Vivo 25: 125-127, 2011.

36 Menditti D, Palomba F and Rullo R: Essential bone defects. Arch Stomatol 30: 547-556, 1989

37 Weibrich G, Kleis WK, Otto M, Gnoth SH, Burwinkel M, Kriegsmann J, Kuffner HD and Wagner W: Cytokeratin expression in botryoid odontogenic cyst. A rare differential keratocyst and ameloblastoma diagnosis. Mund Kiefer Gesichtschir 4: 309-314, 2000.

38 Wysocki GP, Brannon RB, Gardner DG and Sapp P: Histogenesis of the lateral periodontal cyst and the gingival cyst of the adult. Oral Surg Oral Med Oral Pathol 50: 327-334, 1980.

39 Moskow BS and Bloom A: Embryogenesis of the gingival cyst. J Clin Periodontol 10: 119-130, 1983.

40 Amaral-Mendes R and van der Waal I: An unusual clinicoradiographic presentation of a lateral periodontal cyst - report of two cases. Med Oral Patol Oral Cir Buccal 11: 185-187, 2006.

41 Kelsey WP, Kalmar JR and Tatakis DN: Gingival cyst of the adult: regenerative therapy of associated root exposure. A case report and literature review. J Periodontol 80: 2073-2081, 2009

42 Meseli SE, Agrali OB, Peker O and Kuru L: Treatment of lateral periodontal cyst with guided tissue regeneration. Eur J Dent 8: 419-423, 2014.

43 Mori K, Tamura N and Shimada J: Botryoid odontogenic cyst: A case report with immunohistochemical aspects. Asian Journal of Oral and Maxillofacial Surg 23: 31-34, 2011.

44 Weathers DR and Waldron CA: Unusual multilocular cysts of the jaws (botryoid odontogenic cysts). Oral Surg Oral Med Oral Pathol 36: 235-241, 1973.

45 Anuradha A, Urmila U, Srinivas GV, Deviramisetty S and Puneeth HK: Botryoid odontogenic cyst: a diagnostic chaos. J Clin Diagn Res 8: ZD11-ZD12, 2014.

46 Heikinheimo K, Happonen RP, Forssell K, Kuusilehto A and Virtanen I: A botryoid odontogenic cyst with multiple recurrences. Int J Oral Maxillofac Surg 18: 10-13, 1989.

47 Üçok Ö, Yaman Z, Günhan Ö, Üçok C, Doğan N and Baykul T: Botryoid odontogenic cyst: report of a case with extensive epithelial proliferation. Int J Oral Maxillofac Surg 34: 693-695, 2005.

48 Domingues MG, Jaeger MM, Araújo V and Araújo NS: The expression of cytokeratins in human enamel organ. Eur J Oral Sci 108: 43-47, 2000.

49 Cataldo E and Berkman MD: Cysts of the oral mucosa in newborns. Am J Dis Child 116: 44-48, 1968.

50 Van Heerden WFP and Van Zyl AW: Diagnosis and management of oral lesions and conditions in the newborn SA Fam Pract 52: 489-491, 2010.

51 Haveri FTTS and Inamadar AC: A cross sectional prospective study of cutaneous lesions in newborn. Dermatology 1: 1-8, 2014.

52 Kelsey WP, Kalmar JR and Tatakis DN: Gingival cyst of the adult: regenerative therapy of associated root exposure. A case report and literature review. J Periodontol 80: 2073-2081, 2009.
53 Cizmeci MN, Kanburoglu MK, Kara S and Tatli MM: Bohn's nodules: peculiar neonatal intraoral lesions mistaken for natal teeth. Eur J Pediatr 173: 403, 2014.

54 Shimp KL, Bhatnagar KP, Bonar CJ and Smith TD: Ontogeny of the Nasopalatine Duct in Primates. Anat Rec Part A 274: 862-869, 2003.

55 Nelson BL and Linfesty RL: Nasopalatine Duct Cyst. Head and Neck Pathol 4: 121-122, 2010.

56 Peruma CJ: An Unusually Large Destructive Nasopalatine Duct Cyst: A Case Report. J Maxillofac Oral Surg 12: 100-104, 2013.

57 Madani M, Berardi $\mathrm{T}$ and Stoopler ET.: Anatomic and examination considerations of the oral cavity. Med Clin North Am 98: 1225-1238, 2014.

58 Christ TF: The globulomaxillary cyst: an embryological misconception. Oral Surg 30: 515-526, 1970.

59 Harouche EF: Fissural cysts of the maxilla and mandible. Ann Plastic 10: 224-230, 1983.

60 Cavalcante RC, Durski F and Deliberador TM: Le Fort I osteotomy to enucleation of grand proportions fissural cyst presentation of case report. Int J Surg Case Rep 29: 80-84, 2016.

61 Kanas RJ, DeBoom GW and Jensen JL: Inverted heart-shaped, interradicular radiolucent area of the anterior maxilla. J Am Dent Assoc 115: 887-889, 1987.

62 Vedtofte P and Holmstrup P: Inflammatory paradental cysts in the globulomaxillary region. J Oral Pathol Med 18: 125-127, 1989.

63 Dammer U, Driemel O, Mohren W, Giedl C and Reichert TE: "Globulomaxillary cysts: do they really exist? Clin Oral Investig 18: 239-246, 2014.

64 Tsesis I, Rosen E, Dubinsky L, Buchner A and Vered M: Metaplastic changes in the epithelium of radicular cysts. J Clin Exp Dent 8: e529-e533, 2016.

65 Audion M and Siberchicot F: Globulomaxillary cyst. Stomatol Chir Maxillofac 111: 25-26, 2010.

66 Borrás-Ferreres J, Sánchez-Torres A and Gay-Escoda C: Malignant changes developing from odontogenic cysts: A systematic review. J Clin Exp Dent 8: e622-e628, 2016.

67 Aparna M, Gupta M, Sujir N, Kamath A, Solomon M and Radhakrishnan R: Calcifying Odontogenic Cyst: A Rare report of a non-neoplastic variant associated with cholesterol granuloma. J Contemp Dent Pract 14: 1178-1182, 2013.

68 Mittal N, Sah K, Chandra S, Gupta S, Mittal S and Agarwal M: Extraosseous calcifying cystic odontogenic tumor: An uncommon variant. Natl J Maxillofac Surg 4: 245-248, 2013.

69 de Arruda JAA, Monteiro JLGC, Abreu LG, de Oliveira Silva LV, Schuch LF, de Noronha MS, Callou G, Moreno A, and Mesquita RA: Calcifying odontogenic cyst, dentinogenic ghost cell tumor, and ghost cell odontogenic carcinoma: A systematic review. J Oral Pathol Med, 2018. doi: 10.1111/jop.12727. [Epub ahead of print].

70 Jamshidi S, Zargaran M, Roshanaei G, Hadadi F, and Dehghani Nazhvani A: Immunohistochemical comparison of the expression of CD34 and CD105 in odontogenic keratocyst and dentigerous cyst. J Dentistry 18: 43-49, 2017.

71 Padayachee A and Van Wyk CW: Two cystic lesions with features of both the botryoid odontogenic cyst and the central mucoepidermoidtumour: Sialo-odontogenic cyst? J Oral Pathol 16: 499-504, 1987.

72 Naruse T, Yamashita K, Yanamoto S, Rokutanda S, Matsushita $\mathrm{Y}$, Sakamoto $\mathrm{Y}$ and Umeda $\mathrm{M}$ : Histopathological and 
immunohistochemical study in keratocystic odontogenic tumors: Predictive factors of recurrence. Oncol Lett 13: 34873493, 2017.

73 Kotwaney S and Shetty P: Orthokeratinized odontogenic cyst: A milder variant of an odontogenic keratocyst. Univ Res J Dent 3: 101-103, 2013.

74 Menditti D, Laino L, Nastri L, Caruso U, Fiore P and Baldi A: Oral angioleiomyoma: a rare pathological entity. In Vivo 26 : 161-163, 2012.

75 Dos Santos JN, Oliveira GQ, Gurgel CA, de Souza RO, Sales $\mathrm{CB}$, de Aguiar Pires Valença NA and Ramos EA: Altered expression of cytokeratins in primary, recurrent and syndrome keratocystic odontogenic tumors. J Mol Histol 40: 269-275, 2009.

76 Aragaki T, Michi Y, Katsube K, Uzawa N, Okada N, Akashi T, Amagasa T, Yamaguchi A and Sakamoto K: Comprehensive keratin profiling reveals different histopathogenesis of keratocystic odontogenic tumor and orthokeratinized odontogenic cyst. Hum Pathol 41: 1718-1725, 2010.

77 Gorlin RJ, Pindborg JJ, Clausen FP and Vickers RA: The calcifying odontogenic cyst - A possible analogue of the cutaneous calcifying epithelioma of Malherbe. An analysis of fifteen cases. Oral Surg Oral Med Oral Pathol 15: 1235-1243, 1962.

78 Praetorius F, Hjørting-Hansen E, Gorlin RJ and Vickers RA: Calcifying odontogenic cyst. Range, variations and neoplastic potential. Acta Odontol Scand 39: 227-240, 1981.

79 Channappa NK, Krishnapillai R and Rao JB: Cystic variant of calcifying epithelial odontogenic tumor. J Investig Clin Dent 3: 152-156, 2012

80 Borrás-Ferreres J, Sánchez-Torres A, Aguirre-Urizar JM and Gay-Escoda C: Dentigerous cyst with parietal and intracystic calcifications: A case report and literature review. J Clin Exp Dent 10: e296-e299, 2018.

81 Murakami S, Koike Y, Matsuzaka K, Ohata H, Uchiyama T and Inoue T: A case of calcifying odontogenic cyst with numerous calcifications: immunohistochemical analysis. Bull Tokyo Dent Coll 44: 61-66, 2003.

82 Lucchese A, Scivetti M, Pilolli GP and Favia G: Analysis of ghost cells in calcifying cystic odontogenic tumors by confocal laser scanning microscopy Oral Surg Oral Med Oral Pathol Oral Radiol Endod 104: 391-394, 2007.

83 Fregnani ER, Pires FR, Quezada RD, Shih IM, Vargas PA and De Almeida OP: Calcifying odontogenic cyst: clinicopathological features and immunohistochemical profile of 10 cases. J Oral Pathol Med 32: 163-170, 2003.

84 Mehendiratta M, Bishen KA, Boaz K and Mathias Y: Ghost cells: A journey in the dark. Dent Res J 9: S1-S8, 2012.

85 Moghadam SA, Moghadam FA, Mokhtari S and Eini E: Immunohistochemical Analysis of P63 Expression in Odontogenic Lesions. BioMed Res Int 1: 57, 2013.

86 Gardner DG, Kessler HP, Morency R and Schaner DL: The glandular odontogenic cyst: An apparent entity. J Oral Pathol 17: 359-366, 1988.

87 Kaplan I, Anavi Y and Hirshberg A: Glandular odontogenic cyst: a challenge in diagnosis and treatment. Oral Dis 14: 575581,2008

88 Figueiredo RN, Dinkar AD and Khorate MM: Glandular odontogenic cyst of the maxilla: a case report and literature review. Pan Afr Med J 25: 116, 2016.
89 Fowler CB, Brannon RB, Kessler HP, Castle JT and Kahn MA: Glandular odontogenic cyst: analysis of 46 cases with special emphasis on microscopic criteria for diagnosis Head Neck Pathol 5: 364-375, 2011.

90 Vered M, Allon I, Buchner A and Dayan D: Is maspin immunolocalization a tool to differentiate central low-grade mucoepidermoid carcinoma from glandular odontogenic cyst? Acta Histochem 112: 161-168, 2010.

91 Mascitti M, Santarelli A, Sabatucci A, Procaccini M, Lo Muzio L, Zizzi A and Rubini C: Glandular odontogenic cyst: Review of literature and report of a new case with cytokeratin-19 expression. Open Dent J 8: 1-12, 2014.

92 Pires FR, Chen SY, da Cruz Perez DE, de Almeida OP and Kowalski LP: Cytokeratin expression in central mucoepidermoid carcinoma and glandular odontogenic cyst. Oral Oncol 40: 545-551, 2004.

93 Lo Muzio L, Santarelli A, Caltabiano R, Rubini C, Pieramici T, Fior A, Trevisiol L, Carinci F, Leonardi R, Bufo P, Lanzafame $\mathrm{S}$ and Piattelli A: P63 expression in odontogenic cysts. Int $\mathrm{J}$ Oral Maxillofac Surg 34: 668-673, 2005

94 Gardner DG: Pseudocysts and retention cysts of the maxillary sinus. Oral Surg Oral Med Oral Pathol 58: 561-567, 1984.

95 Gardner DG and Gullane PJ: Mucoceles of the maxillary sinus. Oral Surg Oral Med Oral Pathol 62: 538-543, 1986.

96 Menditti D, Palomba F, Rullo R and Minervini G: Cysts and pseudocysts of the maxillary sinus. Arch Stomatol 31: 39-49, 1990.

97 Meer S and Altini M: Cysts and pseudocysts of the maxillary antrum revisited. SADJ 61: 10-13, 2006.

98 Rivis $\mathrm{M}$ and Valeanu AN: Giant maxillary cyst with intrasinusal evolution. Rom J Morphol Embryol 54: 889-892, 2013.

99 Lindsay JR: Non secreting cysts of the maxillary sinus mucosa. Laryngoscope 52: 84-100, 1942.

100 Hartmann S and Grandis JR: Treatment of head and neck cancer in the elderly. Expert Opin Pharmacother 17: 1903-1921, 2016.

101 Al-Belasy FA: Inferior meatal antrostomy: is it necessary after radical sinus surgery through the Caldwell-Luc approach? J Oral Maxillofac Surg 62: 559-562, 2004.

102 Huang YC and Chen WH: Caldwell-Luc operation without inferior meatal antrostomy: a retrospective study of 50 cases. J Oral Maxillofac Surg 70: 2080-2084, 2012.

103 Giotakis EI and Weber RK: Cysts of the maxillary sinus: a literature review. Int Forum Allergy Rhinol 3: 766-771, 2013.

104 Rapaport BH and Heggie AA: Simple bone cyst of the mandibular condyle. Ann Maxillofac Surg 6: 314-315, 2016.

105 Hillerup S and Hjørting-Hansen E: Aneurysmal bone cyst-simple bone cyst, two aspects of the same pathologic entity? Int J Oral Surg 7: 16-22, 1978.

106 Zadik Y, Aktaş A, Drucker S and Nitzan DW: Aneurysmal bone cyst of mandibular condyle: A case report and review of the literature. J Craniomaxillofac Surg 40: 243-248, 2012.

107 Oliveira AM and Chou MM: USP6-induced neoplasms: the biologic spectrum of aneurysmal bone cyst and nodular fasciitis. Hum Pathol 45: 1-11, 2014.

108 Kumar N, Kohli M, Pandey S and Tulsi SP: Cystic hygroma. Maxillofac Surg 1: 81-85, 2010.

109 Yang X, Ow A, Zhang CP, Wang LZ, Yang WJ, Hu YJ and Zhong LP: Clinical analysis of 120 cases of intraoral lymphoepithelial cyst. Oral Surg Oral Med Oral Pathol Oral Radiol 113: 448-452, 2012. 
110 Sameer KS, Mohanty S and Correa MM: Lingual thyroglossal duct cysts- a review. Das K. Int J Pediatr Otorhinolaryngol 76: 165-168, 2012.

111 Klestadt WD: Nasal cysts and the facial cleft cyst theory. Ann Otol Rhinol Laryngol 62: 84-92, 1953.

112 Suresh BV and Vorak S: Huge Plunging Ranula. Maxillofac. Oral Surg 11: 487-490, 2012.

113 Allard RH: Dissertations 25 years after date. Non-odontogenic cysts of the oral regions. Ned Tijdschr Tandheelkd 113: 278283, 2006.

114 Falcis GM, Verli FD, Consolaro A and dos Santos CR: Morphological characterization of the nasopalatine region in human fetuses and its association to pathologies. J Appl Oral Sci 21: 250-255, 2013.

115 Toribio Y and Roehrl MH: The nasolabial cyst: a nonodontogenic oral cyst related to nasolacrimal duct epithelium. Arch Pathol Lab Med 135: 1499-1503, 2011

116 Parwani R, Parwani S and Wanjari S: Diagnosis and management of bilateral nasolabial cysts. J Oral Maxillofac Pathol 17: 443-446, 2013.
117 Kurokawa I, Nishimura K, Hakamada A, Isoda K, Yamanaka $\mathrm{K}$, Mizutani $\mathrm{H}$ and Tsubura A: Cutaneous dermoid cyst: cytokeratin and filaggrin expression suggesting differentiation towards follicular infundibulum and mature sebaceous gland. Oncol Rep 16: 295-299, 2006.

118 Aquino R, Laino L, De Marco G, Itro L and Menditti D: Dermoid cysts of the jaw. Intern J Clin Dentistry 3: 24-34, 2010.

119 Baisakhiya N and Deshmukh P: Unusual sites of epidermoid cyst Indian J Otolaryngol Head Neck Surg 63: 149-151, 2011.

120 Bonet C, Peñarrocha-Oltra D, Minguez JM, Vera-Sirera B, Peñarrocha-Diago $\mathrm{M}$ and Peñarrocha-Diago $\mathrm{M}$ : Oral teratomas: a report of 5 cases. J Oral Maxillofac Surg 70: 2809-2813, 2012.

121 Wright JM and Vered M: Update from the 4th Edition of the WHO. Classification of Head and Neck Tumors: Odontogenic and Maxillofacial Bone Tumors. Head and Neck Pathol 11: 6877,2017

Received June 3, 2018

Revised June 16, 2018

Accepted June 21, 2018 